Vol 12, Issue 4, 2019

\title{
IN VITRO ANTIOXIDANT AND PHOTOPROTECTIVE ACTIVITIES OF CARICA PAPAYA FRUITS
}

\author{
SEOW LAY JING, KHOR POH YEN, GOURI KUMAR DASH*
}

Faculty of Pharmacy and Health Sciences, Universiti Kuala Lumpur Royal College of Medicine Perak, 30450 Ipoh, Malaysia. Email: gourikumar@unikl.edu.my

Received: 24 January 2019, Revised and Accepted: 19 March 2019

ABSTRACT

Objective: The objective of the study was to evaluate the antioxidant and photoprotective effects of Carica papaya fruits using spectrophotometric methods.

Methods: The dried fruit powder of $C$. papaya was extracted separately in methanol, ethanol, and distilled water for 2 days on a constant heating water bath at $60^{\circ} \mathrm{C}$. The extracts were concentrated under vacuum using a rotary evaporator and separately dried in a desiccator to yield the methanol, ethanol, and aqueous extracts. Proximate analysis of the fruit powder such as determination of ash values, loss on drying, and extractive values was performed as per the World Health Organization guidelines. Total phenolic and flavonoid contents were determined by Folin-Ciocalteu and aluminum chloride methods, respectively. Antioxidant activities of the extracts were evaluated using 2,2-diphenyl-1-picrylhydrazyl radical scavenging method and compared with ascorbic acid. The photoprotective effect was evaluated by the spectrophotometric method.

Results: Our results revealed the total phenolic content $59.7 \pm 1.15$ for methanol extract, $56.1 \pm 0.33$ for ethanol extract, and $64.4 \pm 1.95$ for the aqueous extract $\mu \mathrm{g} / \mathrm{ml}$ of gallic acid equivalent. The level of flavonoids, expressed in quercetin equivalents in $\mu \mathrm{g} / \mathrm{ml}$, of methanol extract was of $79.3 \pm 0.61$, ethanol extract $66.3 \pm 0.13$, and aqueous extract $23.9 \pm 0.26$, respectively. The free radical scavenging activity of the extracts was found superior to ascorbic acid that was used as the standard for activity comparison. The results of sun protection factor (SPF) in vitro study demonstrated comparable SPF in a concentration-dependent manner.

Conclusion: The flavonoids and phenolic compounds present in the extracts could be responsible by the photoprotective effect of $C$. papaya.

Keywords: Carica papaya L., Proximate analysis, Antioxidant activity, Photoprotective activity.

(C) 2019 The Authors. Published by Innovare Academic Sciences Pvt Ltd. This is an open access article under the CC BY license (http://creativecommons. org/licenses/by/4. 0/) DOI: http://dx.doi.org/10.22159/ajpcr.2019.v12i4.31666

\section{INTRODUCTION}

Oxidative stress develops due to excessive production of reactive oxidant species (ROS) that results into a serious imbalance between endogenous antioxidant defense mechanism and the production of ROS in the body [1]. Consequently, the results of oxidative stress contributes inflammation and development of a number of debilitating illnesses, such as cancer, diabetes, cardiovascular diseases, or neurodegenerative processes. Ultraviolet radiation (UV) induces oxidative stress and inflammatory responses in the skin that causes premature photoaging, immunosuppression, and skin cancer [2]. ROS induced by oxidative stress can ultimately lead to apoptotic or necrotic cell death [3]. Polyphenols are known to possess potential antioxidant and anti-inflammatory effects by inhibiting molecular signaling pathways that are activated due to oxidative stress [4]. Flavonoids absorb UV radiation (photoprotective effect) together with their anti-inflammatory and immunomodulatory properties and act as ROS scavengers [5].

Fruits of Carica papaya L. (Family: Caricaceae) are edible and known worldwide for their delicious taste. The fruits act as a rich source of antioxidant Vitamins A, C, and E together with beta carotene, minerals, fibers, and a digestive enzyme - papain [6]. The fruits are reported to possess several biological activities and now considered to be a valuable neutraceutical fruit plant. Previous biological studies on C. papaya reveals anti-inflammatory, antioxidant, diuretic, antibacterial, abortifacient, hypoglycemic, and immunomodulatory activities [7]. In the present paper, we report the evaluation of the antioxidant and photoprotective effects of $C$. papaya.

\section{MATERIALS AND METHODS}

\section{Plant material}

Fresh fruits of $C$. papaya were collected from the local market in Teluk Intan, Malaysia, and authenticated by Dr. Fatimah Mohamed, Botanist from Universiti Pendidikan Sultan Idris, Tanjung Malim, Perak. The fruits were washed, cut into small pieces, and shade dried followed by grinding to coarse powder using a suitable mechanical grinder. The dried coarse powder was suitably preserved in an airtight container and used for further analysis.

\section{Extraction}

The dried fruit powder was extracted separately in methanol, ethanol, and distilled water for 2 days on a constant heating water bath at $60^{\circ} \mathrm{C}$. Fresh solvent was used for each day of extraction. Similar extracts were combined and concentrated under vacuum using a rotary evaporator. The concentrated extracts were separately dried in a desiccator to yield the methanol, ethanol, and aqueous extracts.

\section{Proximate analysis}

The dried fruit powder was subjected to proximate analysis such as determination of ash values, loss on drying, and extractive values as per the World Health Organization guidelines [8]. All the experiments were done in triplicate.

\section{Antioxidant activity}

Sample preparations

All test samples were accurately weighed and dissolved in methanol (1 $\mathrm{mg} / \mathrm{ml})$.

\section{Determination of total phenolic content}

Total phenolic contents of the extracts $(1 \mathrm{mg} / \mathrm{ml})$ were determined using Folin-Ciocalteu method as described by Shoib and Shahid [9] with minor modifications. Briefly, l ml of crude extracts $(1 \mathrm{mg} / \mathrm{ml})$ were separately mixed thoroughly with $1 \mathrm{ml}$ of Folin-Ciocalteu reagent for $5 \mathrm{~min}$, followed by the addition of $2 \mathrm{ml}$ of $20 \%$ (w/v) sodium carbonate. The mixtures were allowed to stand for a further $60 \mathrm{~min}$ in the dark, 
and absorbance of each solution was measured at $750 \mathrm{~nm}$ against the blank. A similar procedure was repeated for the standard gallic acid solutions $(20-200 \mu \mathrm{g} / \mathrm{ml})$ to obtain the calibration curve with the following equation:

$$
\text { Absorbance }=0.0064 \text { gallic acid }(\mu \mathrm{g})-0.0277\left(\mathrm{R}^{2}=0.9926\right)
$$

The total phenolic content of the test samples, as gallic acid equivalent, was determined using the absorbance of the test sample measured at $750 \mathrm{~nm}$ as input to the standard curve and equation.

\section{Determination of total flavonoid content}

The total flavonoid contents of test samples $(1 \mathrm{mg} / \mathrm{ml})$ were determined as per the method suggested by Rao et al. [10] and Udaya Prakash et al. [11], using quercetin as standard. Each sample (1 $\mathrm{ml})$ was separately mixed with $1 \mathrm{ml}$ of $2 \%$ aluminum chloride solution prepared in methanol. The mixture was incubated for $1 \mathrm{~h}$ at room temperature and the absorbance was measured at $420 \mathrm{~nm}$. The control sample consisted of $1 \mathrm{ml}$ extract solution with $1 \mathrm{ml}$ methanol without aluminum chloride. The calibration curve was constructed using six different concentrations of quercetin solution prepared in methanol ranging from 20 to $200 \mu \mathrm{g} / \mathrm{ml}$. The content of the flavonoids in the extracts was calculated as $\mu \mathrm{g} / \mathrm{ml}$ of quercetin equivalent using the equation obtained from the standard quercetin graph as below:

$$
\text { Absorbance }=0.0116 \text { quercetin }(\mu \mathrm{g})-0.0402\left(\mathrm{R}^{2}=0.9907\right)
$$

\section{The 2,2-diphenyl-1-picrylhydrazil (DPPH) scavenging assay}

The free radical scavenging activity of the test samples was determined by DPPH assay method $[12,13]$ with some modifications. Sample stock solutions $(1.0 \mathrm{mg} / \mathrm{ml})$ of extracts were diluted to final concentrations of $500,400,300,200$, and $100 \mu \mathrm{g} / \mathrm{ml}$ in methanol. $1 \mathrm{ml}$ of sample was added in increasing concentration $(100-500 \mu \mathrm{g} / \mathrm{ml})$ to $3 \mathrm{ml}$ of $0.1 \%$ DPPH solution in methanol, shaken for $5 \mathrm{~min}$, and further kept in the dark for $30 \mathrm{~min}$. The solution of ascorbic acid $(100-500 \mu \mathrm{g} / \mathrm{ml})$ was taken as the standard and $2 \mathrm{ml}$ of methanol with $1 \mathrm{ml}$ DPPH was taken ascontrol. The absorbance of the mixture was then measured at $517 \mathrm{~nm}$. The ability of the sample to scavenge DPPH radical was determined from:

$$
\% \text { Scavenging }=\frac{\left(\begin{array}{l}
\text { Absorbance of control }- \\
\text { Absorbance of test sample }
\end{array}\right)}{\text { Absorbance of control }} \times 100
$$

\section{Determination of sun protection factor (SPF)}

The SPF was evaluated as suggested by Fonseca and Rafaela [14] with minor modifications. Each test extract was diluted in methanol separately to a final concentration of $200 \mu \mathrm{l} / \mathrm{ml}$ and placed at $37^{\circ} \mathrm{C}$ in the dark conditions. All measurements of SPF were performed using a Perkin-Elmer UV spectrophotometer with wavelengths ranging between 290 and $320 \mathrm{~nm}$ with intervals of $5 \mathrm{~nm}$ after every reading. The readings were taken in triplicate. The absorbance values were multiplied with the respective EE $(\lambda)$ values. Their summation was taken and multiplied with the correction factor (10) to obtain final SPF values.

$$
\text { SPF spectrophotometric }=\mathrm{CF} \times \sum_{290}^{320} \mathrm{EE}(\lambda) \times \mathrm{I}(\lambda) \times \operatorname{Abs}(\lambda)
$$

Where:

EE $(\lambda)$ : Erythemal effect spectrum; I $(\lambda)$ : Solar intensity spectrum; Abs $(\lambda)$ : Absorbance of sunscreen product; CF: Correction factor $(=10)$.

\section{RESULTS AND DISCUSSION}

Proximate analysis

The results of the proximate analysis of $C$. papaya are shown in Table 1. Determination of ash values, extractive values, and loss on drying are important parameters to ensure the quality of herbal drugs. Measurement of ash content is a measure of the total amount of minerals in plant drugs, whereas the extractive values represent the nature of phytochemicals they contain. Determination of loss on drying represents the amount of moisture within the plant drugs.

\section{Determination of total phenolic and flavonoid content}

The results from the quantitative determination of phenolic and flavonoids are summarized in Table 2. The most significant total phenolic content was of $59.7 \pm 1.15$ for methanol extract, $56.1 \pm 0.33$ for ethanol extract, and $64.4 \pm 1.95$ for the aqueous extract $\mu \mathrm{g} / \mathrm{ml}$ of gallic acid equivalent. The level of flavonoids, expressed in quercetin equivalents, in $\mu \mathrm{g} / \mathrm{ml}$ of methanol extract was of $79.3 \pm 0.61$, ethanol extract $66.3 \pm 0.13$, and aqueous extract $23.9 \pm 0.26$, respectively.

\section{Antioxidant activity (DPPH)}

The results of the DPPH scavenging activity is presented in Fig. 1. This test has been widely recommended to measure the antioxidant activity of different phenolic compounds in plant drugs. DPPH is characterized as one of the few stable radicals by virtue of the delocalization of the spare electron over the molecule as a whole so that the molecule does not dimerize as would be the case with most other free radicals. When a solution of DPPH is mixed with that of a substrate that can donate a hydrogen atom, then it gives rise to the reduced form of the radical which is accompanied by loss of color [15]. Our experiment revealed excellent free radical scavenging activity of the extracts, superior to ascorbic acid that was used as the standard for activity comparison.

\section{Determination of SPF}

The spectrophotometric determination of UVB protection of a sun care product is a reliable in vitro measurement for economical, practical, and ethical reasons [16]. The SPF in vitro was determined using the

Table 1: Proximate analysis of Carica papaya

\begin{tabular}{ll}
\hline Parameter & Result (w/w\%) \\
\hline Total ash & $16.6 \pm 0.29$ \\
Acid-insoluble ash & $2.25 \pm 0.01$ \\
Water-soluble ash & $2.89 \pm 0.02$ \\
Loss on drying & $17.6 \pm 0.18$ \\
Water extractive values & $17.8 \pm 0.20$ \\
Ethanol extractive values & $15.0 \pm 0.02$ \\
\hline
\end{tabular}

Results are expressed as mean \pm SD from three observations

Table 2: Total phenolic and flavonoid content of Carica papaya extracts

\begin{tabular}{lll}
\hline $\begin{array}{l}\text { Test } \\
\text { sample (extracts) }\end{array}$ & $\begin{array}{l}\text { Total phenolic } \\
(\boldsymbol{\mu g} / \mathbf{m l})\end{array}$ & $\begin{array}{l}\text { Total flavonoid } \\
(\boldsymbol{\mu g} / \mathbf{m l})\end{array}$ \\
\hline Aqueous & $64.4 \pm 1.95$ & $23.9 \pm 0.26$ \\
Ethanol & $56.1 \pm 0.33$ & $66.3 \pm 0.13$ \\
Methanol & $59.7 \pm 1.15$ & $79.3 \pm 0.61$ \\
\hline
\end{tabular}

Results are expressed as mean \pm SD from three observations

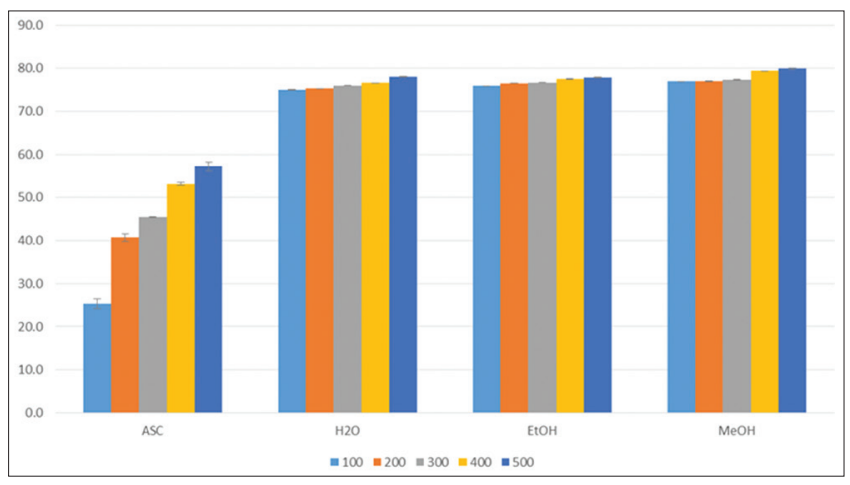

Fig. 1: Antioxidant activity of Carica papaya extracts 


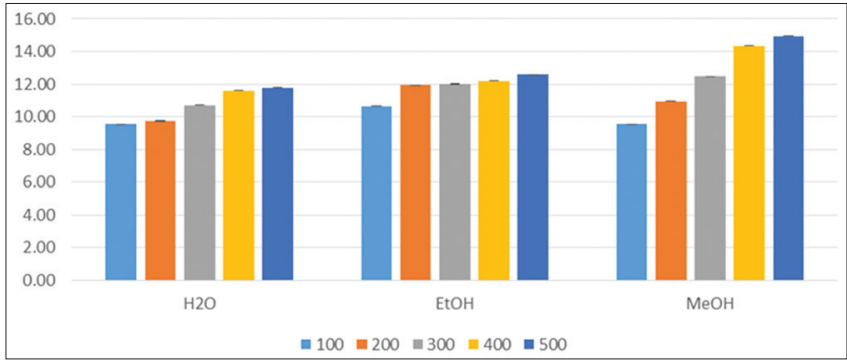

Fig. 2: Sun protection factors of Carica papaya extracts

UVB region in the spectrophotometric analysis which is considered to be the ideal region of the greatest incidence of exposure by people during day time. Our results (Fig. 2) demonstrated comparable SPF in a concentration-dependent manner.

\section{CONCLUSION}

In summary, the present study demonstrates that $C$. papaya contains a good amount of phenolic compounds which may serve as natural sources of antioxidants agents. The flavonoids present in the extracts could be responsible by photoprotective effect presented in this study. Further research is still under progress in our laboratory to reach the substance responsible for antioxidant and photoprotective activities of extracts.

\section{AUTHORS' CONTRIBUTIONS}

The first author Dr. Seow Lay Jing is the principal investigator of the present research work who designed the work, collected the materials for the study, and prepared the manuscript. The second author Miss. Khor Poh Yen performed the experiment and the corresponding author Dr. Gouri Kumar Dash prepared and reviewed the manuscript for publication.

\section{CONFLICTS OF INTERESTS}

The authors declared no conflicts of interest.

\section{REFERENCES}

1. Lugrin J, Rosenblatt-Velin N, Parapanov R, Liaudet L. The role of oxidative stress during inflammatory processes. Biol Chem 2014;395:203-30.

2. Raimundo GO, Camila SA, Grasielly RS, Amanda LG, Ana PO, Sarah RG, et al. In vitro antioxidant and photoprotective activities of dried extracts from Neoglaziovia variegata (Bromeliaceae). J Appl Pharm Sci 2013;3:122-7.

3. Narendhirakannan RT, Hannah MA. Oxidative stress and skin cancer: An overview. Indian J Clin Biochem 2013;28:110-5.

4. Hussain T, Tan B, Yin Y, Blachier F, Tossou MC, Rahu N. Oxidative stress and inflammation: What polyphenols can do for us? Oxid Med Cell Longev 2016;2016:7432797.

5. Saewan N, Jimtaisong A. Photoprotection of natural flavonoids. J Appl Pharm Sci 2013;3:129-41.

6. Vij T, Prashar Y. A review on medicinal properties of Carica papaya Linn. Asian Pac J Trop Dis 2015;5:1-6.

7. Roshan A, Verma NK, Gupta A. A brief study on Carica papaya - A review. Int J Curr Trend Pharm Res 2014;2:541-50.

8. World Health Organisations. WHO Monographs on Selected Medicinal Plants. Geneva: World Health Organisations; 2000.

9. Shoib AB, Shahid AM. Determination of total phenolic and flavonoid content, antimicrobial and antioxidant activity of a root extract of Arisaema jacquemontii Blume. J Taibah Univ Sci 2015;9:449-54.

10. Rao US, Abdurrazak M, Mohd KS. Phytochemical screening, total flavonoid and phenolic content assays of various solvent extracts of tepal of Musa paradisiaca. Malaysian J Anal Sci 2016;20:1181-90.

11. Udaya Prakash NK, Ranjithkumar M, Sripriya N, Lakshmi P, Deepa S, Bhuvaneswari S. Antioxidant, free radical scavenging activity and GCMS studies on Pedilanthustithymaloides (L.) poit. Int J Pharm Pharm Sci 2014;6:284-7.

12. Siddiqua A, Premakumari KB, Sultana R, Vithya, Savitha. Antioxidant activity and estimation of total phenolic content of Muntingia calabura by colorimetry. Int J Chem Tech Res 2010;2:205-8.

13. Charoonratana T, Settharaksa S, Madaka F, Songsak T. Screening of antioxidant activity and total phenolic content in Raphanus sativus pod. Int J Pharm Pharm Sci 2014;6:224-6.

14. Fonseca A, Rafaela N. Determination of sun protection factor by UVVis spectrophotometry. Health Care Curr Rev 2013;1:108.

15. Alam MN, Bristi NJ, Rafiquzzaman M. Review on in vivo and in vitro methods evaluation of antioxidant activity. Saudi Pharm J 2013;21:143-52.

16. Pissavini M, Ferrero L, Alard V, Heinrich U, Tronnier H, Kockott D, et al. Determination of the in vitro SPF. Cosmetics Toietories Mag 2003; 118:63-72. 